\title{
Delayed traveling ionospheric disturbances, especially in equatorial regions, following geomagnetic activity
}

\author{
G. G. Bowman and I. K. Mortimer \\ Department of Physics, The University of Queensland, Brisbane, Qld., 4072, Australia
}

(Received October 28, 2002; Revised August 25, 2003; Accepted September 1, 2003)

\begin{abstract}
For the Western-Pacific region spread-F has been found to occur with delays after geomagnetic activity (GA) ranging from 5 to 10 days as station groups are considered from low midlatitudes to equatorial regions. The statistical (superposed-epoch) analyses also indicate that at the equator the spread-F, and therefore associated medium-scale traveling ionospheric disturbances (MS-TIDs) occur with additional delays around 16, 22 and 28 days representing a 6-day modulation of the delay period. These results are compared with similar delays, including the modulation, for D-region enhanced hydroxyl emission (Shefov, 1969). It is proposed that this similarity may be explained by MS-TIDs influencing both the F and D regions as they travel. Long delays of over 20 days are also found near the equator for airglow-measured MS-TIDs (Sobral et al., 1997). These are recorded infrequently and have equatorward motions, while normally eastward motions are measured at the equator. Also in midlatitudes D-region absorption events have been shown (statistically) to have similar long delays after GA. It is suggested that atmospheric gravity waves and associated MS-TIDs may be generated by some of the precipitations responsible for the absorption. The recording of the delayed spread-F events depends on the GA being well below the average levels around sunset on the nights of recording. This implies that lower upper-atmosphere neutral particle densities are necessary.
\end{abstract}

Key words: MS-TIDs, Spread-F, geomagnetic activity, low latitudes.

\section{Introduction}

An early analysis (McNicol et al., 1956) as well as subsequent investigations (Bowman, 1990, 1991; Bowman and Monro, 1988; Bowman et al., 1994) have shown that for midlatitude locations, medium-scale traveling ionospheric disturbances (MS-TIDs) are responsible for ionogram-recorded spread-F occurrence. The spread traces result primarily from off-vertical radiowave specular reflections. For example McNicol et al. (1956) have detected 82 spread-F associated MSTIDs traveling mostly in northwest directions, with speeds varying from 42 to $97 \mathrm{~ms}^{-1}$. Results from equatorial latitudes suggest a similar reflection mechanism (Flaherty et al., 1996; Sales et al., 1996; Weber et al., 1996; Wright et al., 1996). The analyses for this investigation involve an examination of the delayed occurrence, after geomagnetic activity (GA), of spread-F. A range of stations of different latitudes have been used, including equatorial stations.

The subdivision into groups of ionosonde stations around the world from subauroral to equatorial regions, in terms of their L-shell locations, is indicated by Table 1, although it will be used here for the Western-Pacific region. Some sample stations from this region are also listed in Table 1. Earlier investigations (Bowman, 1979, 1982) which considered world-wide stations by superposed-epoch (SE) analyses with daily $A_{P}$ indices as key days, were able to establish that delays did occur. These ranged from 0.5 days for subauroral stations to several days for central midlatitude locations. Fur-

Copy right $(\mathrm{c}$ The Society of Geomagnetism and Earth, Planetary and Space Science (SGEPSS); The Seismological Society of Japan; The Volcanological Society of Japan; The Geodetic Society of Japan; The Japanese Society for Planetary Sciences. thermore the delays were shorter for higher levels of GA. For example Table 2 lists delays recorded for different GA levels for central midlatitude locations (group 4). Also, for example, the corresponding delays for group 2 were 2.0, 1.0 and 0.6 days. Other evidence for shorter delays of a day or so for individual high-midlatitude stations has been reported by Bowman (1992a) and Bowman and Mortimer (2003).

Most of the analyses will involve sunspot-minimum years (1971-1977), but sunspot-maximum years will also be used. Here the delays will be examined from group 5 to the group 8 equatorial stations. Earlier, as Table 2 shows, group 4 was shown to register delays as large as 3 days. Two particular papers, which will be discussed, seem important to this investigation. One relates to delays after GA experienced by D-region hydroxyl emissions (Shefov, 1969). This investigation has also considered airglow measurements by Sobral et al. (1997) which detected equatorward moving MSTIDs at an equatorial location. These can be considered as distinct from MS-TIDs normally measured near the equator with eastward components of velocity (see results and references given by Sobral et al., 1985, and Sobral and Abdu, 1991). Here MS-TIDs with equatorward movements will be called type A MS-TIDs and those with eastward components type B. This paper will also consider delays after GA of D-region absorption because of some similarities with the spread-F delays. The literature on the subject is summarised by Sato (1981). In addition satellite particle-precipitation events reported by Nagata et al. (1988) have been analysed for evidence of delays after GA.

In the Discussion and Conclusions section an attempt will 
Table 1. Spread-F groups.

\begin{tabular}{cll}
\hline Group & Subdivisions & Stations \\
\hline 1 & Subauroral & Hobart \\
& $\begin{array}{l}2.6 \leq \mathrm{L}<3.3 \\
\text { High midlat. } 1 .\end{array}$ & Christchurch \\
& $2.2 \leq \mathrm{L}<2.6$ & \\
& High midlat. 2. & Canberra \\
3 & $1.8 \leq \mathrm{L}<2.2$ & \\
& Central midlat. & Brisbane \\
4 & $1.5 \leq \mathrm{L}<1.8$ & \\
& Low midlat. & Townsville \\
5 & $1.25 \leq \mathrm{L}<1.5$ & \\
& Low latitude & Yamagawa \\
6 & $1.10 \leq \mathrm{L}<1.25$ & \\
7 & Anomaly-crest lat. & Chung-Li \\
8 & Equatorial lat. & Manila \\
\hline
\end{tabular}

Table 2. Group 4 stations (after Bowman, 1982).

\begin{tabular}{cc}
\hline$A_{P}$ index & Delays (days) \\
\hline $15<\mathrm{AP} \leq 35$ & 3.5 \\
$35<\mathrm{AP} \leq 70$ & 1.5 \\
$70<\mathrm{AP} \leq 150$ & 1.0 \\
\hline
\end{tabular}

be made to reconcile the remarkable similarity between delays after GA of D-region hydroxyl emissions (Shefov, 1969) and spread-F occurrence (Table 2), at least from subauroral to central midlatitude locations. For these emissions the SE analyses required normalization as is the case for spread-F. These hydroxyl delays have been tracked all the way to the equator, which the present investigation has considered for spread-F. Shefov (1969) reports on delays " - a few days after the commencement of a geomagnetic storm and last up to 30 days. The delay in time depends on the latitude, and on the vicinity of the equator is about 10 days". Another feature of Shefov's results, which seems important, is the existence of a 6-day periodicity in the enhancements, following the initial delayed emissions. Thus with this periodicity, delays at the equator can be expected to be approximately 10, 16, 22 and 28 days. Delays of similar durations will be examined here for spread-F at equatorial stations. Tables 3 and 4 list respectively geomagnetic coordinates for the geomagnetic or ionosonde stations used for these analyses.

\section{Data and Methods of Analysis}

Valuable as they are in other respects, examinations of individual MS-TIDs are unlikely to reveal much information on their possible associations with GA (Bowman et al., 1994; Saito et al., 2002; Ogawa et al., 2002). Instead this present investigation has used the statistical approach employing the SE technique. For several decades now information on spread-F occurrences has been available from ionosonde results in the form of monthly bulletins of ionospheric parameters at hourly intervals from stations around the world. The use of the descriptive letter $(\mathrm{F})$ on the $f_{o} F_{2}$ values has allowed nightly estimates of spread-F occurrence
Table 3. Geomagnetic coordinates for geomagnetic stations.

\begin{tabular}{lll}
\hline Barrow & 68.54 & 241.15 \\
College & 64.63 & 256.52 \\
Dixon & 63.02 & 161.57 \\
Cape Wellen & 61.79 & 237.30 \\
Tixie Bay & 60.44 & 191.41 \\
\hline
\end{tabular}

Table 4. Geomagnetic coordinates for ionosonde stations.

\begin{tabular}{lrr}
\hline Hobart & -51.71 & 224.29 \\
Christchurch & -48.07 & 252.78 \\
Canberra & -43.99 & 224.29 \\
Irkutsk & 41.02 & 174.38 \\
Brisbane & -38.74 & 226.87 \\
Wakkanai & 35.27 & 206.04 \\
Akita & 29.47 & 205.45 \\
Townsville & -28.47 & 218.79 \\
Tokyo & 25.44 & 205.41 \\
Yamagawa & 20.30 & 197.81 \\
Okinawa & 15.25 & 195.58 \\
Chung Li & 14.27 & 191.55 \\
Manila & 03.37 & 189.78 \\
Huancayo & -00.62 & 353.81 \\
Kodaikanal & 00.57 & 147.10 \\
\hline
\end{tabular}

in hours per night for the stations used here. These nightly estimates have been normalized by dividing each entry in any month by the average occurrence for that month. This was necessary as, for the spread-F considered here, occurrences varied significantly for the annual and sunspot-cycle variations. These variations are presumably independent of the day-to-day GA variations. It should be noted that for whatever reason (see however Bowman (1994)) the changes over these intervals for levels of the upper-atmosphere neutral particle density (NPD) are very similar (Bowman, 1992b). The date for the first half of the night was used. High controls were assessed from values $\geq 1.33$ times each monthly average value and low controls for values $\leq 0.50$ times the averages.

Some of the data from the analyses reported here are taken from the airglow measurements of Sobral et al. (1997). These measurements were made at Cachoeira Paulista (dip $28^{\circ} \mathrm{S}$ ) an equatorial station in Brazil. This paper lists 40 events recorded from 1977 to 1984 (inclusive). The parameter f-min has also been analysed, again using SE methods for events at Christchurch, Irkutsk and Brisbane. Controls are obtained for $\mathrm{H}$-component analyses for f-min values $\geq 1.33$ times median values for a central hour or two hours either side. The control hour was 1500 local time (LT) for Christchurch and Irkutsk, and 1200 LT for Brisbane. From the OHZORA satellite, the precipitation of electrons and protons totalling 166 events recorded from March 1984 to September 1986 and listed by Nagata et al. (1988) have been used as controls for an $\mathrm{H}$-component $\mathrm{SE}$ analysis.

Hourly values of either the AE, AL or AU index or the geomagnetic $\mathrm{H}$ component at a range of stations will be used as data in SE analyses with key days (controls) selected from 
AU INDEX VERSUS CACHOEIRA PAULISTA EQUATORIAL MS-TIDs

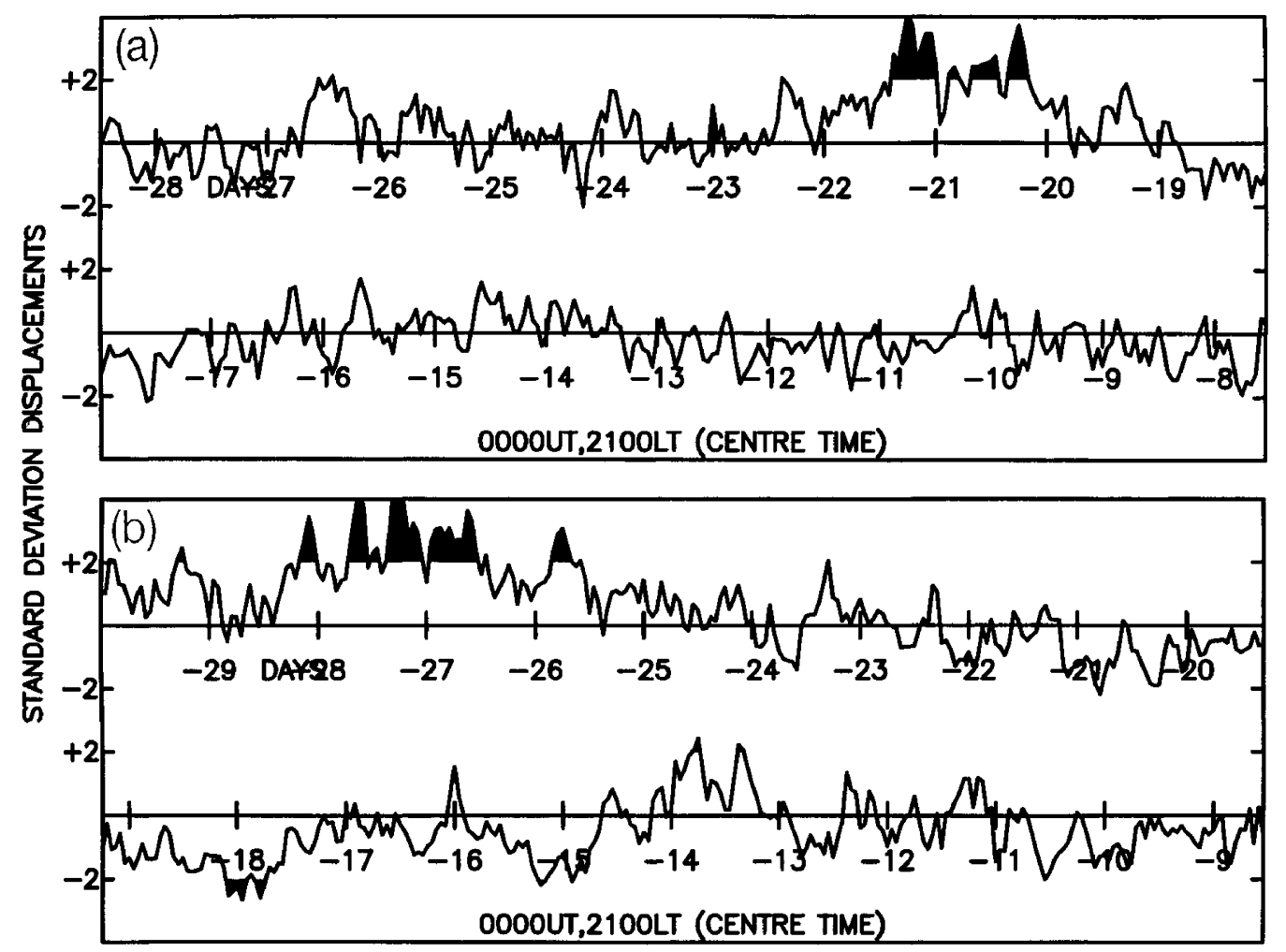

Fig. 1. Analysis results of GA relative to Cachoeira Paulista MS-TIDs airglow events listed by Sobral et al. (1997), showing delays (a) $\approx 21$-day for 15 events in 1978 and 1983, and (b) $\approx 27$-day for 12 events in 1979 and 1980 . The figures indicate different delays in different years

spread-F occurrence levels. The analyses will centre mainly on stations in the Western-Pacific area, although two additional equatorial stations will be used. The analyses are capable of detecting delays as large as 30 or 35 days. The AE, $\mathrm{AL}$ and $\mathrm{AU}$ indices are all treated as positive in the analyses and, as shown by Mayaud (1980), the H component analyses can be expected to give either positive or negative results of importance. After the SE columnar additions were obtained for the H-component analyses the daily average for each station was subtracted for each day, thus obtaining values representative of departures from average behaviour (Bowman and Shrestha, 1998). As mentioned SE methods have been used throughout. These involve establishing an array of data points in lines, one after another, plotting a particular parameter at specific intervals (e.g. hours, days or months) relative to (before and after) control events recorded by another parameter. The columns of this array are then added and averaged in the hope of finding a significant displacement which would indicate some association between these parameters. The analyses used here embraced many days of GA. Most involve the centre hour \pm 30 days (or 1441 hours) so that for the final summations the displacements from the mean are distributed normally. These are expressed as standard-deviation displacements from the mean. Thus the statistical significance of any displacement can be assessed. Only small interesting sections of the extensive plots obtained from these analyses are presented here. The centre hour used has been 0000 Universal Time (UT) for the date of each spread-F entry. The local time of any position on a plot can be determined from this reference time. The larger dis- placements have been blacked out above an arbitrary value of two standard deviations, thus highlighting certain positions on the plots.

Using hourly values of GA and nightly estimates of spread-F occurrences, earlier analyses (Bowman, 1993, $1994,1996,1998$ ) have shown that generally delayed spreadF occurrences were related to GA at specific local times which were the early morning hours of the ionosondes station used. Hours around midnight and 0600 LT were particularly involved. From these results it seemed likely that the enhanced GA of interest was independent of any particular hour of the night for spread-F occurrence. This method has also revealed a suppression of GA at specific times in the daylight hours (1200 and 1800 LT) immediately preceding the nights of spread-F occurrence (Bowman, 1995, 1998). Using the same method of analysis the results to be shown here are as expected from previous results (see for example results to be given for Manila and Kodaikanal)

\section{Results}

The results to be presented will detail (a) MS-TID equatorial airglow measurements, (b) delayed spread-F occurrence (delays recorded to the nearest hour) for stations ranging from group 5 to group 8, and (c) the possibility that D-region absorption may be involved in the generation of MS-TIDs.

\subsection{Type A MS-TID equatorial airglow measurements}

For the equatorial airglow-measured MS-TIDs mentioned earlier (Sobral et al., 1997) there was no apparent association with GA at the times of recording. The disturbances probably had shallow wave amplitudes as no spread-F was 
AU INDEX VERSUS GROUP 5 SPREAD-F

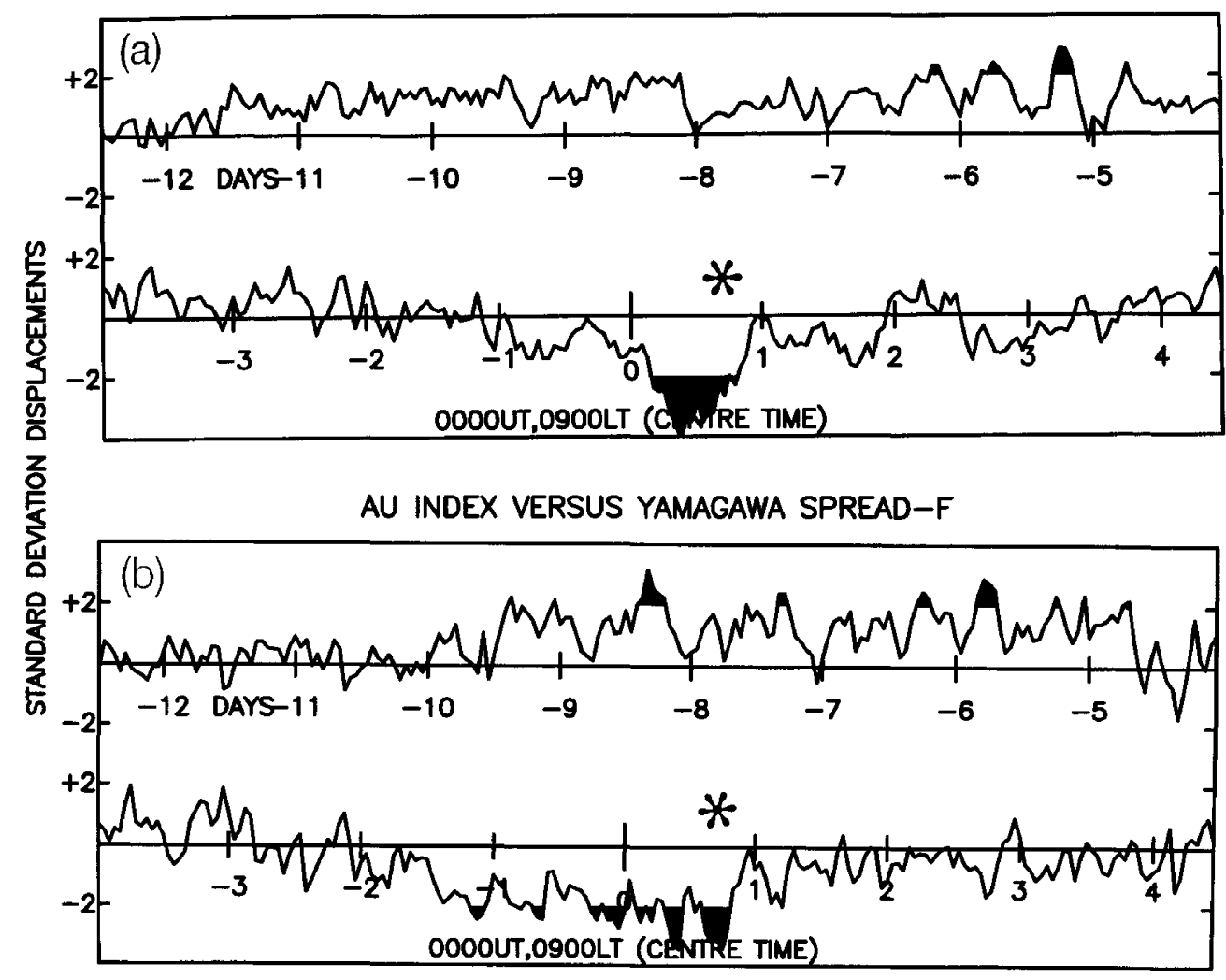

Fig. 2. GA relative to spread-F events for (a) group 5 stations and (b) a group 6 station, Yamagawa, showing significant delays for (a) 5 days and (b) 6 and 8 days. Both figures show suppressed GA hours before spread-F occurrence.

$\triangle H$ COMPONENTS (3 STATIONS) VERSUS CHUNG-LI \& OKINAWA SPREAD-F

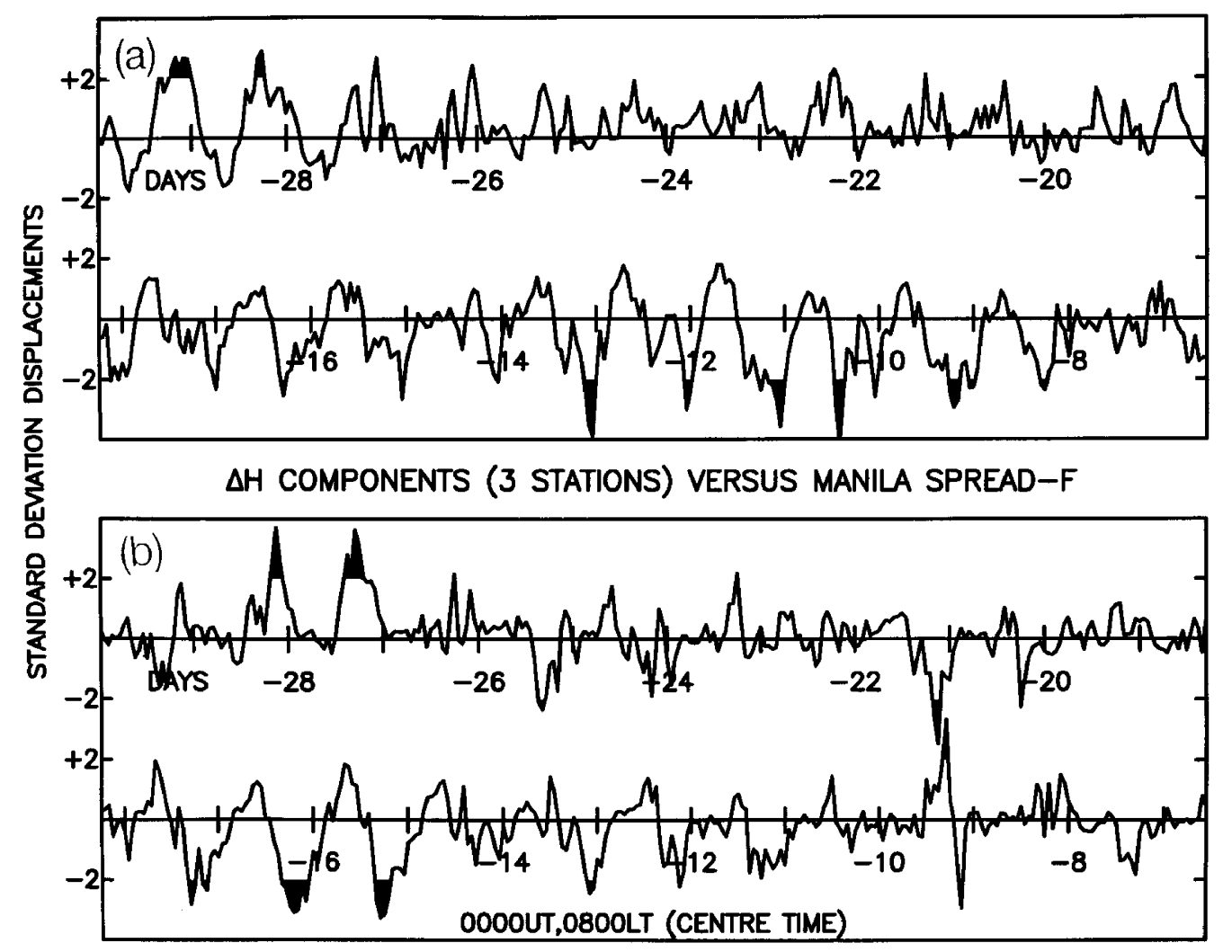

Fig. 3. H-component analyses for spread-F (a) $320 R_{z}$-max events for group 7 stations (Chung-Li and Okinawa) and (b) $564 R_{z}$-max events for a group 8 station (Manila). Note consecutive delays (a) near 10-13 days and (b) 15-17 days. 
AU INDEX VERSUS R $R_{\mathbf{z}}-$ MIN. MANILA SPREAD-F HIGHS

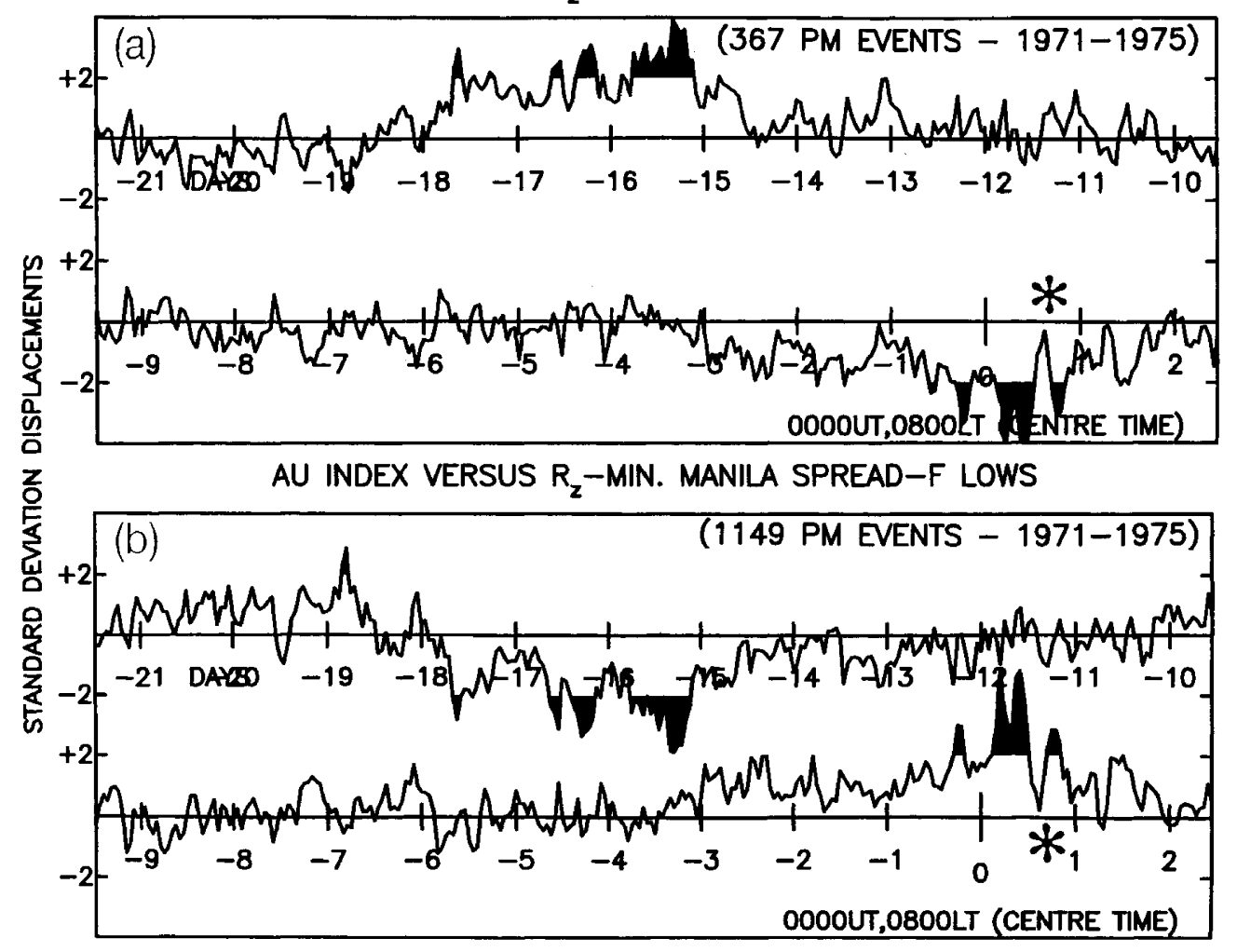

Fig. 4. Delays of importance using AU index analyses for Manila near 16 days (a) positive (b) negative for high and low controls respectively. Significant displacements of opposite signs in hours before spread-F occurrence.

recorded on ionograms. An interesting feature is that the samples given of the ionospheric macroscale changes when the MS-TIDs arrive (figure 4 of Sobral et al., 1997) are virtually the same as those found for the MS-TIDs responsible for spread-F in midlatitudes (Bowman, 1990). A simple manual inspection of each of these airglow-recorded MS-TID events with $K_{P}$ values shows a marked tendency for GA to peak around 27 or 21 days earlier. Using the AU index and treating each year separately, SE analyses have shown one or other of these delays (depending on the year) at high levels of significance. Rather than illustrating each year separately, the results for the years 1978 and 1983 have been combined and presented by Fig. 1(a) for the 21-day delays, as have the years 1979 and 1980 for the 27-day delays (Fig. 1(b)).

\subsection{Delayed spread-F occurrence}

Table 2 shows, from previous work, that group 4 spread-F delays can be as high as 3.5 days. For average spread-F levels of Townsville, Akita and Tokyo (group 5) Figure 2(a) indiciates the most significant delay to occur at 5 days. Group 6 stations are represented by Yamagawa for which Figure 2(b) shows a range of delays with the maximum displacement occurring for a delay of 8 days. All the AE indices have been used as positive so that negative displacements can be interpreted as suppressed GA. As has been noted earlier (Bowman, 1995, 1998) the recording of spread-F at these and other stations depends to a large extent on GA being suppressed around the sunset hours, for the nights of spreadF occurrence. Possible reasons for this will be mentioned in Section 4. Spread-F occurrence for Chung Li and Okinawa (group 7 stations) has been investigated using GA as recorded by the geomagnetic $\mathrm{H}$ component. The auroral stations Tixie Bay, Cape Wellen and College were used. Analyses of this type will give results where GA can be recorded as significant by displacements which can be either negative (related to the AL index) or positive (related to the AU index) (Mayaud, 1980). Thus Figure 3(a) shows, for group 7, significant negative displacements with delays ranging from 9 to 13 days. Positive displacements are also recorded at days 28 and 29. Similar observations can be made from Fig. 3(b) for Manila (a group 8 equatorial station) with delays (negative displacements) near 15, 16, 17, 20 and 21 days, with other delays (positive displacements) near 27 and 28 days. It may not be a coincidence (Fig. 3(b)) that a 6-day periodicity can be recognized using delays of 15, 21 and 27 days, which are the more important displacements. High or low spreadF controls at Manila are also considered by a SE analysis using the AU index. Similar to the H-component analysis (Fig. 3(b)) significant displacements are found indicating delays around 16 days (Fig. 4(a)). Again it is shown that one of the conditions which allows the recording of above-average levels of spread-F is the existence of low levels of GA, particularly in the hours of 1300 and 1800 LT on the recording days of interest (Fig. 4(a)). Another feature illustrated by Fig. 4(b), the result of an analysis using low-level controls, is the recording of a "mirror image" of the positive results shown in Fig. 4(a). Analyses which use the SE method will reveal associations relative to the average levels of the parameter being investigated (GA in this case). Therefore the negative displacements on Fig. 4(b) can be explained if delayed spread-F also occurs for average GA levels. 
AL INDEX VERSUS $R_{\mathbf{z}}$-MAX. HUANCAYO SPREAD-F HIGHS

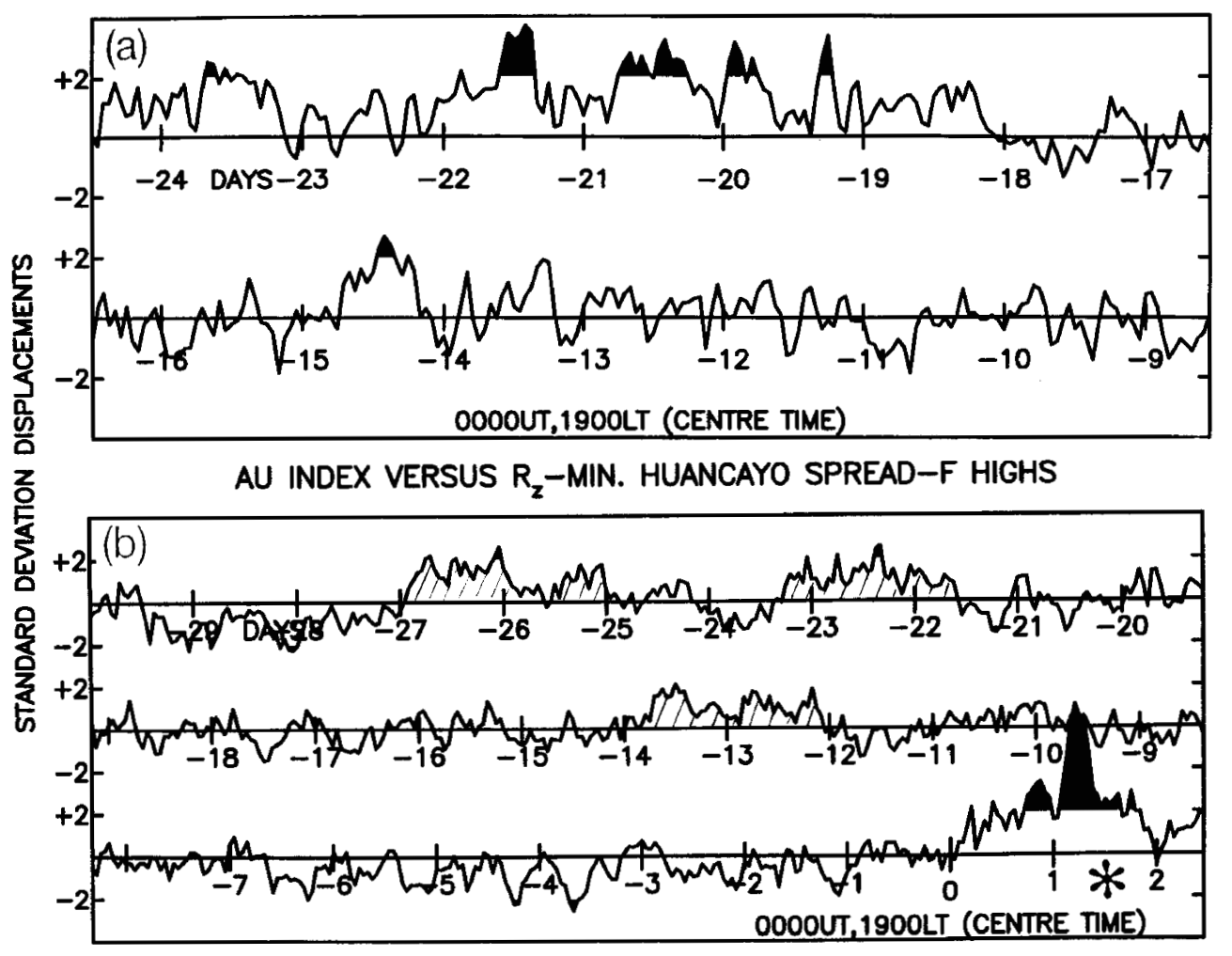

Fig. 5. Delays of importance using AL analyses for Huancayo near 21 or 22 days during (a) $R_{z}$-max and (b) $R_{z}$-min. The positive displacement near midnight for (b) possibly associated with the generation of LS-TIDs.

Table 5. Equatorial spread-F delays.

\begin{tabular}{cl}
\hline Days & \multicolumn{1}{c}{ Figures } \\
\hline 10 & $3(\mathrm{a}), 6(\mathrm{a})$ \\
16 & $3(\mathrm{~b}), 4(\mathrm{a}), 6(\mathrm{~b})$ \\
22 & $1(\mathrm{a}), 5(\mathrm{a})$ \\
28 & $1(\mathrm{~b}), 3(\mathrm{a}), 3(\mathrm{~b})$ \\
\hline
\end{tabular}

Results for two other equatorial stations (Huancayo and Kodaikanal), outside the Western-Pacific region, are found to be consistent with the equatorial results reported here. For Huancayo the pre-midnight (PM) period of sunspotmaximum years (Fig. 5(a)) a delay around 21 days is well defined, while for an after-midnight (AM) period of sunspotminimum years, delays which are not well-defined, are recorded for days 22 and 26 (Fig. 5(b)). The more interesting feature of this figure is the significant positive displacement ( 7 standard deviations) around midnight on nights of high spread-F occurrence, which the controls represent. For other periods investigated (see Fig. 4(a)) negative displacements are normally recorded prior to the nights representing the controls. For this period large-scale traveling ionospheric disturbances (LS-TIDs) are known to be responsible for spread-F in the pre-sunrise period. On Fig. 5(b) the asterisk is placed at $0600 \mathrm{LT}$. These high levels of GA a few hours before the spread-F are in all probability responsible for the generation of atmospheric gravity waves (AGWs) which are in turn responsible for the LS-TIDs (see Bowman,
2001). Figures 8 and 9 of Bowman (1995) give further examples of this phenomenon. The results for Kodaikanal are given in Fig. 6, an interesting aspect being delays registered for a number of consecutive days. Using data from the December solstice months, delays ranging from 7 to 10 days are recorded (Fig. 6(a)). However Figure 6(b) reports results (data for equinoctial months were used) of delays which maximize near 15 days but extend from 12 to 16 days.

In the Introduction it was explained that, for the hydroxyl emission results indicated for equatorial regions, delays of magnitudes 10, 16, 22 and 28 days were expected. The spread-F results which have been presented here give delays which are reasonably consistent with these expectations for hydroxyl emissions. To summarize these spread-F results Table 5 lists the figure locations in this paper which can at least be matched to $10,16,22$ and 28 day delays.

\subsection{D-region absorption}

It has been known for some time that, somewhat similar to that experienced by spread-F occurrence (Table 2), D-region absorption (such as that measured by f-min) is delayed progressively as lower latitude stations are considered. One proposal has suggested that AGWs and related MS-TIDs are generated as a result of some of the D-region precipitation events responsible for the absorption (Bowman, 2000). Sato (1981) investigated this delayed absorption over a range of stations and detailed the literature on the subject. One result (Sato, 1981), which is relevant here, indicated the measurement of absorption of "-llong duration, sometimes more than a fortnight".

Using f-min recordings as controls an investigation into 
AU INDEX VERSUS $R_{\mathbf{z}}-$ MIN. KODAIKANAL SPREAD-F HIGHS

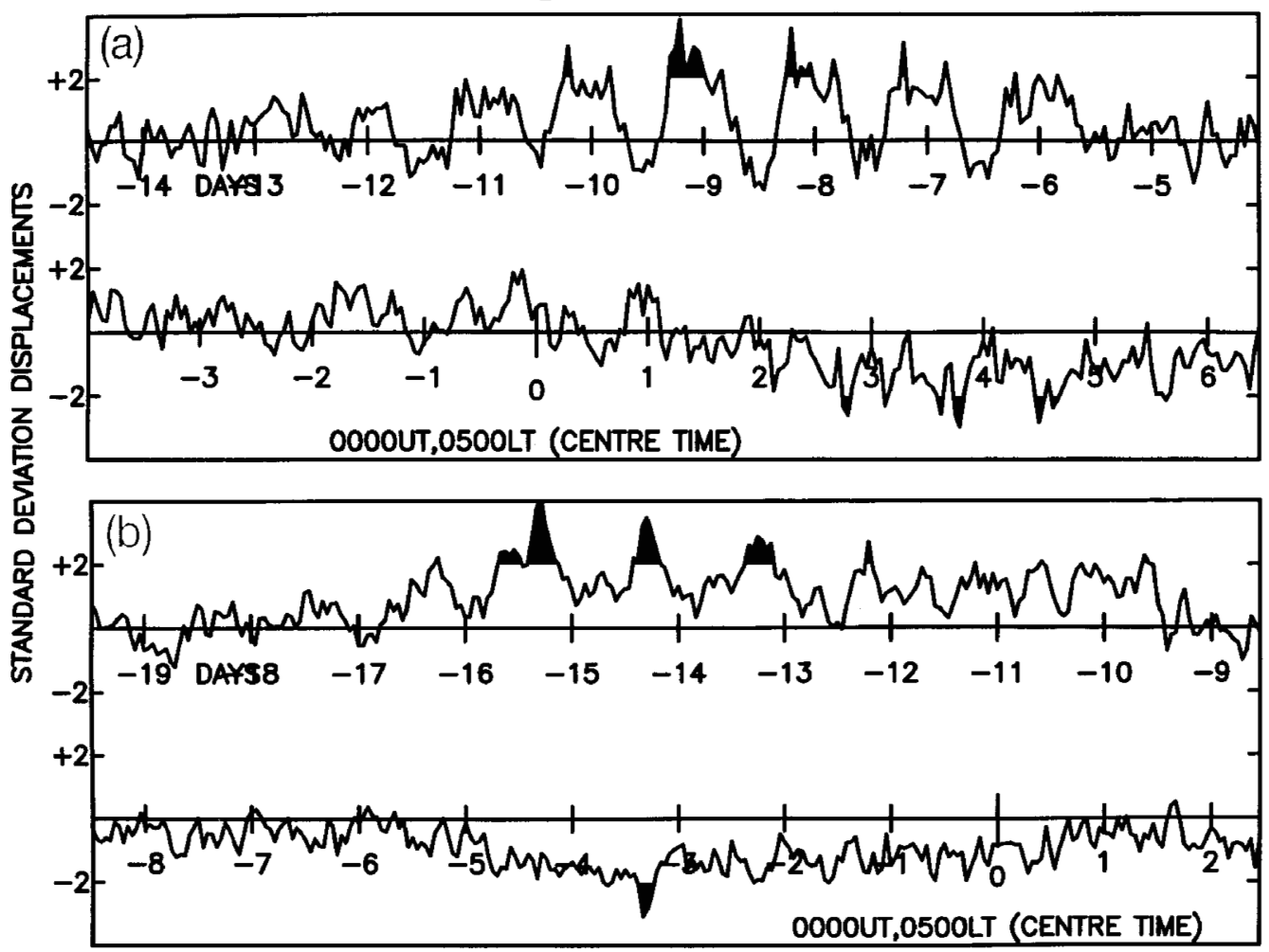

Fig. 6. Delays of importance using AU Index Analyses ( $R_{z}$-min) for Kodaikanal (a) 9 days for December solstice months (151 events) and (b) 15 days for equinoctial months (161 events). Note delays on consecutive days in (a) and (b).

this delayed absorption at Christchurch and Irkutsk has, using H-component analyses, not only shown the change in delay with latitude, but also (statistically) the existence of delays over several consecutive days (Fig. 7), somewhat similar to the consecutive spread-F delays recorded on the spreadF figures (particularly Figs. 3 and 6). For Christchurch the auroral stations were the same as for Fig. 3 and Tixie Bay and Dixon were used for Irkutsk. The Irkutsk plot has delays which are as long as 10 days. Sato (1981) was able to measure absorption at stations as equatorward as Wakkanai. Wakkanai and Brisbane (which have similar latitudes) have been investigated for delayed absorption by a method similar to that for Christchurch and Irkutsk. Both analyses showed a delay around 27 days. The Brisbane results are presented in Fig. 8(a) where delays are shown on consecutive days extending from 23 to 31 days. Similar results were obtained by two analyses which used controls obtained by subdividing the controls for Fig. 8(a).

Also of interest here are the precipitation events measured by the OHZORA satellite involving energetic electrons and protons (Nagata et al., 1988). Figure 8(b) results from using these OHZORA events as controls in an H-component analysis. The delayed occurrence on consecutive days of these precipitations is not only around 6 and 15 days, but of particular interest here, around 27 days. Wakkanai and Brisbane are located on L-shells of 1.6 and 1.5 respectively, which can be compared with the OHZORA precipitation areas (L-shells 1.6-1.8). The analyses used for Figs. 8(a) and 8(b) used the same auroral stations as those used for Fig. 3.

\section{Discussion and Conclusions}

The earlier analyses of delays after GA for world-wide spread-F occurrence (Bowman, 1979, 1982) have found the existence of delays of several days (Table 2) up to central midlatitude locations (group 4). These present analyses have investigated the delayed occurrence for individual stations in the Western-Pacific region at locations equatorward of group 4 stations. It has been shown that the initial delay for low midlatitude stations is 5 days (Fig. 2(a)), for low latitudes 8 days (Fig. 2(b)) and equatorial latitudes 10 days (Figs. 3 and 4). Further, delays around 16, 22 and 28 days are also found for the equatorial station of Manila (Fig. 3(b)). Also this 6day modulation of delays has been found for the equatorial stations of Huancayo and Kodaikanal at other longitude locations (Table 5). High levels of statistical significance are recorded for many of the interesting displacements. Analyses involving the airglow measured MS-TIDs near the equator (Sobral et al., 1997) have also indicated the existence of long delays after GA. An interesting aspect for these particular MS-TIDs is that this delayed occurrence can be recognized for individual events. The spread-F results are very similar to those found for enhanced D-region hydroxyl emissions (Shefov, 1969).

It seems important to discuss the levels of significance of the results presented here. The percentage probabilities of certain selected displacements on the figures being random are (a) $5.7 \times 10^{-5}$ for the $5.0 \sigma$ displacement on Fig. 1(b), (b) $1.5 \times 10^{-2}$ for $3.8 \sigma$ on Fig. $6(a)$ and (c) $4.1 \times 10^{-3}$ for $4.1 \sigma$ on Fig. 6(b) (Croxton, 1949). Similar assessments can be made for other major displacements on the figures. For Manila Fig- 
$\triangle H$ COMPONENTS ( 3 STATIONS) VERSUS $\mathrm{f}-\mathrm{min}$ ABSORPTION

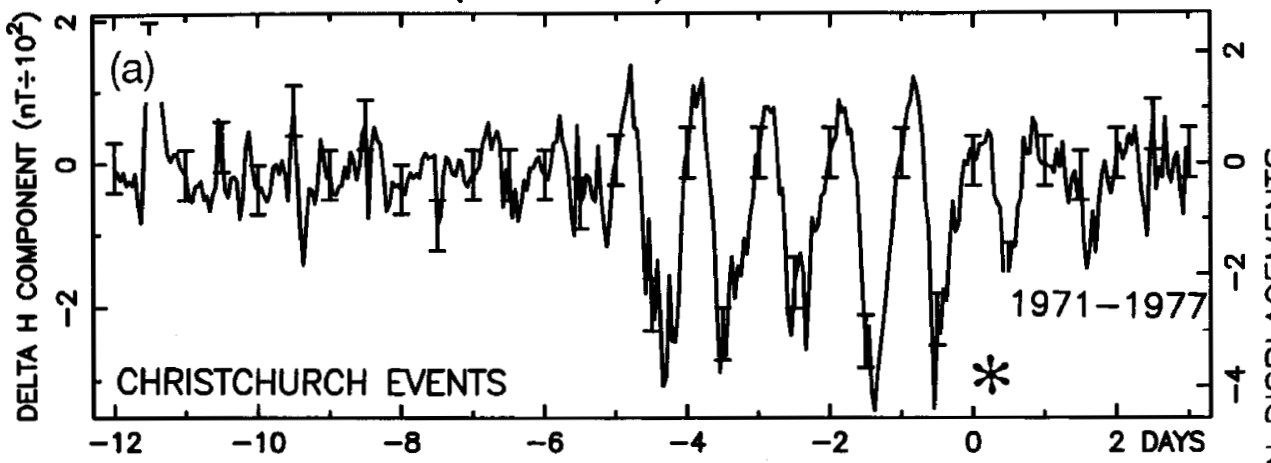

$\triangle H$ COMPONENTS (2 STATIONS) VERSUS $\mathrm{f}-\mathrm{min}$ ABSORPTION

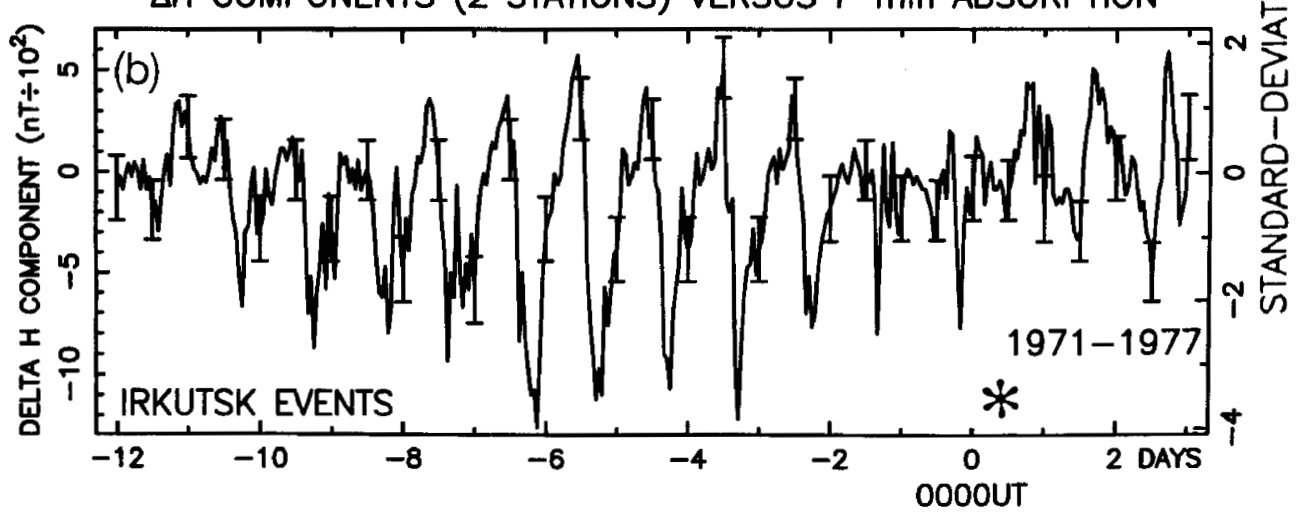

Fig. 7. H-component analyses showing important fmin absorption delays on consecutive days (a) around 2 days for 172 Christchurch events and (b) around 5 days for 153 Irkutsk events. Larger delays for the lower latitude are indicated.

ures 4(a) and 4(b) show distributions one being the "mirror image" of the other. Both figures have significant displacements (around $4 \sigma$ ) representing the same delays (around 15 days). These distributions were found using independent sets of controls and the results seem unlikely to occur by chance. Although not shown here a similar "mirror image" has been found for Fig. 5(a) (Huancayo). Other analyses have often produced results of this kind. Also there is a tendency for important displacements to occur on (statistically) consecutive days; and sometimes this occurs on five or more occasions (Figs. 6, 7 and 8). Thus statistical analyses would seem to have provided good evidence which shows that nighttime MS-TIDs at stations from low midlatitudes to the equator occur at times which indicate delays following GA. What is much less certain is the origin of these disturbances. It has been speculated that AGWs (associated with the MS-TIDs) may be generated as a result of some of the precipitations responsible for D-region absorption. Both the spread-F and absorption events have been shown to have similar delays after GA, particularly the long delays which occur on consecutive days for both phenomena. MS-TIDs originating around midday in midlatitudes (see Fig. 8) would be able to reach the equator during the night which follows. Quite apart from any association which might exist with spread-F occurrence the delays (after GA) for the OHZORA satellite precipitations (Fig. 8(b)) are by themselves, of interest.

Recent evidence (Bowman et al., 1994; Bowman and Mortimer, 2002) and an examination of the literature (Bowman and Mortimer, 2002) has suggested that as MS-TIDs travel, they influence both the $\mathrm{F}$ and $E_{S}$ layers in the iono- sphere. Also there is microbarograph evidence that at times this coupling may extend to ground level (see references given by Bowman and Mortimer, 2002). Thus it might be expected that as MS-TIDs propagate disturbance levels will change in the $F_{2}$ layer (spread-F) and also possibly in the Dregion (enhanced hydroxyl emission). It has been shown that the ionosphere can be influenced by planetary waves (Vincent, 1984; Apostolov et al., 1994). Provided that spread-F occurrence is associated with D-region precipitation events as has been suggested, the possibility exists that 5-6 day planetary waves (Parish et al., 1994; Isoda et al., 2002; Yamada, 2002) may influence the D-region in such a way as to increase the chances of precipitation events. Figures 2 and 4 show that a necessary condition for spread-F occurrence on nights when it is shown to be delayed is that GA needs to be well below its average level around sunset. Associated NPD levels (Priester et al., 1967; Barlier et al., 1978) will therefore be suppressed. This suppression influences all latitudes up to the equator a short time after GA (Prolss and Ocko, 2000). Since it is known (Bowman, 1992b) that there is an inverse relationship between spread-F occurrence and NPD levels, spread-F is more likely to be recorded at these times.

If as seems likely the MS-TIDs associated with the spreadF occurrence considered here are generated at locations poleward of the spread-F recording stations they will have at least equatorward components of velocity. In this case they can be regarded as type A events (see Introduction). Midlatitude MS-TIDs have been found to have equatorward motions (see for example McNicol et al., 1956). Results by Sobral et al. (1997) have been quoted and analysed here. Over a period 


\section{$\triangle H$ COMPONENTS (3 STATIONS) VERSUS $\mathrm{f}-\mathrm{min}$ ABSORPTION}
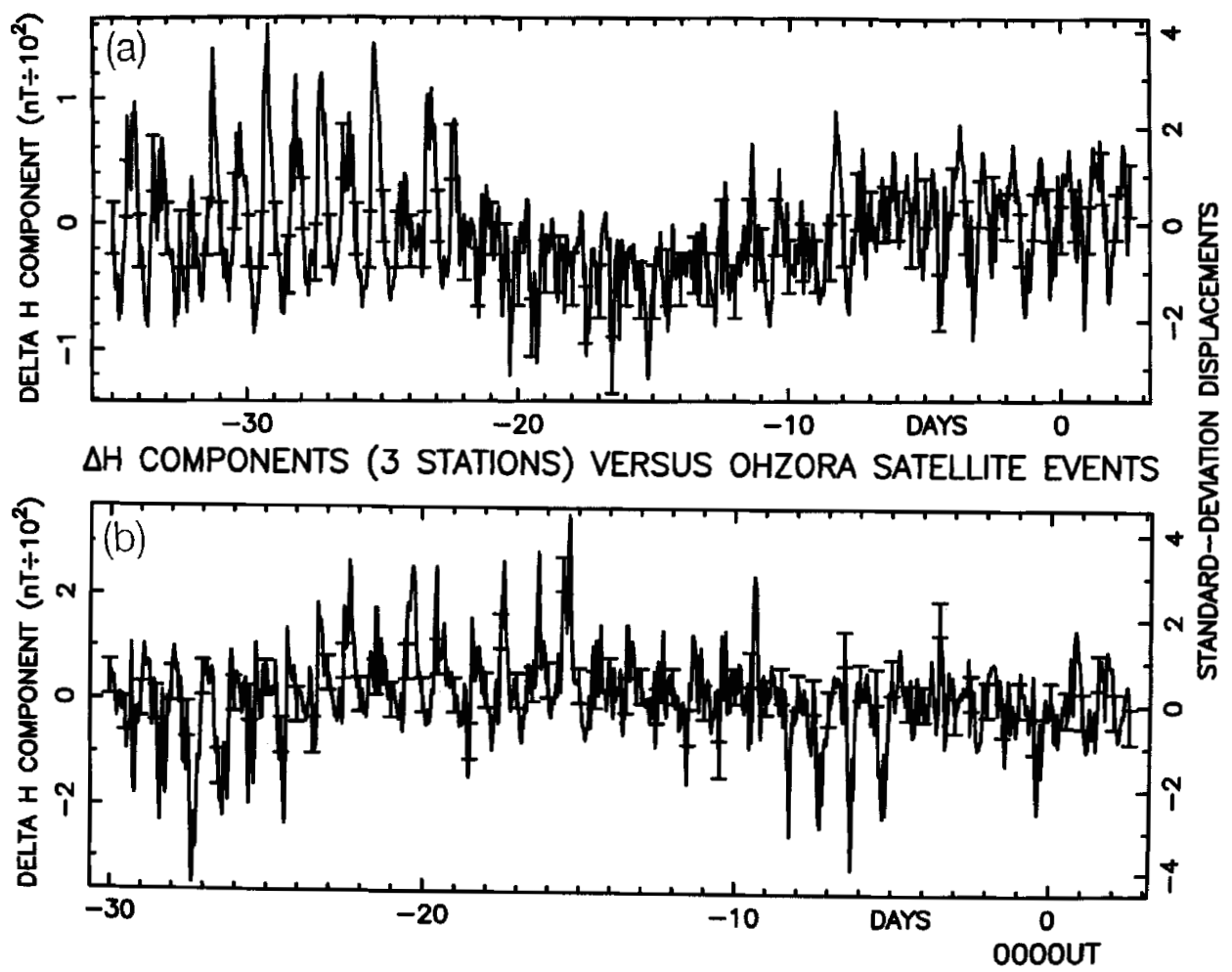

Fig. 8. H-component analyses showing important delays around 30 days for (a) $361 R_{z}$-max Brisbane events (1978-1982) and (b) 166 OHZORA precipitation events (1984-1987). Both analyses record delays on consecutive days as with spread-F occurrence.

of 8 years and at an equatorial location they have detected 40 cases of equatorward-moving MS-TIDs. These results are contrary to other investigations of MS-TIDs events by Bowman et al. (1994) and Shiokawa et al. (2002). Both analyses tracked isolated MS-TIDs moving in south-west directions over Japan with little or no evidence of their reaching the equatorial anomaly-crest station of Okinawa. These results suggested a limiting latitude for these MS-TIDs. Shiokawa et al. (2002) propose an "equatorward limit of medium scale traveling ionospheric disturbances (TIDs) in the middle latitudes." Besides the airglow events the spread-F results presented here are not consistent with the existence of a limiting latitude.

Acknowledgments. The authors would like to thank the World Data Center-C2 for Geomagnetism, Kyoto, Japan for making available the geomagnetic $\mathrm{H}$ components for a number of stations.

\section{References}

Apostolov, A. M., L. Alberca, and D. Altidill, Solar cycle and seasonal behaviour of quasi-two- and five-day oscillations in the time variations of $f_{o} F_{2}$, Ann. Di Geofisica, 37, 187-192, 1994.

Barlier, F., C. Berger, J. L. Falin, G. Kockarts, and G. Thuillier, A thermospheric model based on satellite drag data, Ann. Geophys., 34, 9-24, 1978.

Bowman, G. G., Latitude dependence of the time delay in spread-F occurrence following geomagnetic activity, J. Atmos. Terr. Phys., 41, 999 1004, 1979

Bowman, G. G., Spread-F occurrence in mid- and low-latitude regions related to various levels of geomagnetic activity, J. Atmos. Terr. Phys., 44, 585-589, 1982.

Bowman, G. G., A review of some recent work on mid-latitude spread-F occurrence as detected by ionosondes, J. Geomag. Geoelectr., 42, 109$138,1990$.
Bowman, G. G., Nighttime mid-latitude travelling ionospheric disturbances associated with mild spread-F conditions, J. Geomag. Geoelectr., 43 899-920, 1991.

Bowman, G. G., Delayed mid-latitude spread-F occurrence following enhanced geomagnetic activity, Indian J. Radio Space Phys., 21, 80-88, 1992a.

Bowman, G. G., Upper atmosphere neutral-particle density variations compared with spread-F occurrence rates at locations around the world, Ann. Geophys., 10, 676-682, 1992b.

Bowman, G. G., Daytime and nighttime ionospheric disturbances and their delayed occurrence after geomagnetic activity, Indian J. Radio Space Phys., 22, 1-10, 1993.

Bowman, G. G., Short-term delays in the occurrence of mid-latitude ionospheric disturbances following other geophysical and solar events, J. Geomag. Geoelectr., 46, 297-309, 1994.

Bowman, G. G., Short-term delays in ionogram-recorded equatorial spreadF occurrence after both solar and geomagnetic activity, Ann. Geophys., 13, 1331-1342, 1995.

Bowman, G. G., The influence of $10.7 \mathrm{~cm}$ solar-flux variations on midlatitude daytime ionospheric disturbance conditions, J. Geophys. Res., 101, 10,849-10,854, 1996.

Bowman, G. G., Short term delays (hours) of ionospheric spread-F occurrence, at a range of latitudes, following geomagnetic activity, J. Geophys. Res., 103, 11,627-11,634, 1998.

Bowman, G. G., Associations between tropospheric gravity waves and enhanced geomagnetic activity over three sunspot-minimum periods, Indian J. Radio Space Phys., 29, 1-8, 2000.

Bowman, G. G., A comparison of nighttime TID characteristics between equatorial-ionosheric-anomaly crest and midlatitude regions, related to spread-F occurrence, J. Geophys. Res., 106, 1761-1769, 2001.

Bowman, G. G. and P. E. Monro, Mid-latitude range spread and travelling ionospheric disturbances, J. Atmos. Terr. Phys., 50, 215-223, 1988.

Bowman, G. G. and I. K. Mortimer, Ionospheric coupling especially between ionograms-recorded spread-F and sporadic-E enhancements at an equatorial-anomaly-crest station, Chung-Li, J. Geophys. Res., 107(A10), 1992, doi: 1029/2001JA007549, 2002.

Bowman, G. G. and I. K. Mortimer, Influence of geomagnetic activity on the occurrence of midlatitude ionograms-recorded spread-F., Indian J. Radio 
Space Phys., 32, 16-20, 2003.

Bowman, G. G. and K. L. Shrestha, Tropospheric atmospheric gravity waves and their relationship with geomagnetic activity, Indian J. Radio Space Phys., 27, 110-118, 1998.

Bowman, G. G., S. Fukao, M. Yamamoto, and K. Igarashi, MU-radar recorded field-aligned irregularities in the $F_{2}$ region and associated sporadic-E disturbances, J. Geomag. Geoelectr., 46, 873-889, 1994.

Croxton, F. E., Tables of Areas in Two Tails and One Tail of the Normal Curve, Prentice-Hall, Englewood Cliffs, N. J., 1949.

Flaherty, J. P., M. C. Kelley, C. E. Seyler, and T. J. Fitzgerald, Simultaneous VHF and transequatorial HF observations in the presence of bottomside equatorial spread F, J. Geophys. Res., 101, 26811-26818, 1996.

Isoda, F., T. Tsuda, T. Nakamura, Y. Murayama, K. Igaraski, R. A. Vincent, I. M. Reid, A. Nuryanto, and S. I. Manurung, Long-period oscillations in the mesosphere and lower thermosphere at Yamagawa $\left(32^{\circ} \mathrm{N}, 131^{\circ} \mathrm{E}\right)$, Pontianak $\left(0^{\circ} \mathrm{N}, 109^{\circ} \mathrm{E}\right)$ and Christmas Island $\left(2^{\circ} \mathrm{N}, 157^{\circ} \mathrm{W}\right), \mathrm{J}$. Atmos Sol-Terr. Phys., 64, 1055-1067, 2002.

Mayaud, P. N., Derivation, Meaning and Use of Geomagnetic Indices, Geophysical Monograph 22, American Geophysical Union, Washington DC, 1980.

McNicol, R. W. E., H. C. Webster, and G. G. Bowman, A study of "spreadF" ionospheric echoes at night at Brisbane-I, range spreading (experimental), Aust. J. Phys., 9, 247-271, 1956.

Nagata, K., T. Kohno, H. Murakami, A. Nakamoto, N. Hasebe, J. Kikuchi, and T. Doke, Electron (0.19-3.2 MeV) and proton (0.58-35 MeV) precipitations observed by OHZORA satellite at low latitude zones $L=1.6$ 1.8, Planet. Space Sci, 36, 591-606, 1988.

Ogawa, T., N. Balan, Y. Otsuka, K. Shiokawa, T. Shimomai, and A. Saito, Observations and modeling of $630 \mathrm{~nm}$ airglow and total electron conten associated with traveling ionospheric disturbances over Shigaraki, Japan, Earth Planets Space, 54, 45-56, 2002.

Parish, H. F., J. M. Forbes, and F. Kamalabadi, Planetary wave and solar emission signatures in the equatorial electrojet, J. Geophys. Res., 99 355-368, 1994.

Priester, W., M. Roemer, and H. Volland, The physical behavior of the upper atmosphere deduced from satellite drag data, Space Sci. Rev., 6, 707-780, 1967.

Prolss, G. W. and M. Ocko, Propagation of upper atmosphere storm effects towards lower latitudes, Adv. Space Res., 26, 131-135, 2000.

Saito, A., M. Nishimura, M. Yamamoto, S. Fukao, T. Tsugawa, S. Miyazaki, and M. C. Kelly, Observations of traveling ionospheric disturbances and 3-m irregularities in the nighttime F-region ionosphere with the MU radar and a GPS network, Earth Planets Space, 54, 31-44, 2002.

Sales, G. S., B. W. Reinisch, J. L. Scali, and C. Dozois, Spread F and the structure of equatorial ionization depletions in the southern anomaly region, J. Geophys. Res., 101, 26,819-26,827, 1996.

Sato, T., Geomagnetic control of the winter anomaly in absorption of radio waves in mid-latitudes, J. Geophys. Res., 86, 9137-9151, 1981.

Shefov, N. N., Hydroxyl emission of the upper atmosphere-1. The behaviour during a solar cycle, seasons and geomagnetic disturbances, Planet. Space Sci., 17, 797-813, 1969.

Shiokawa, K., Y. Otsuka, M. K. Ejiri, Y. Sahai, T. Kadota, C. Ihara, T. Ogawa, K. Igarashi, S. Miyazaki, and A. Saito, Imaging observations of the equatorward limit of midlatitude traveling ionospheric disturbances, Earth Planets Space, 54, 57-62, 2002.

Sobral, J. H. A., M. A. Abdu, and Y. Sahai, Equatorial plasma bubble eastward velocity characteristics from scanning airglow photometer measurements over Cachoeira Paulista, J. Atmos. Terr. Phys., 47, 895-900, 1985.

Sobral, J. H. A. and M. A. Abdu, Solar activity effects on equatorial plasma bubble zonal velocity and its latitude gradient as measured by airglow scanning photometers, J. Atmos. Terr. Phys., 53, 729-742, 1991.

Sobral, J. H. A., G. L. Borba, M. A. Abdu, I. S. Batista, H. Sawant, C. J. Zamlutti, H. Takahashi, and Y. Nakamura, Post-sunset wintertime 630.8 $\mathrm{nm}$ airglow perturbations associated with gravity waves at low latitudes in the South American sector, J. Atmos. Terr. Phys., 59, 1611-1623, 1997.

Vincent, R. A., MF/HF radar measurements of the dynamics of the mesopause region - a review, J. Atmos. Terr. Phys., 46, 961-974, 1984.

Weber, E. J., S. Basu, T. W. Bullett, C. Valladares, G. Bishop, K. Groves, H. Kuenzler, P. Ning, P. J. Sultan, R. E. Sheehan, and J. Araya, Equatorial plasma depletion precursor signatures and onset observed at $11^{\circ}$ south of the magnetic equator, J. Geophys. Res., 101, 26829-26838, 1996.

Wright, J. W., P. E. Argo, and M. L. V. Pitteway, On the radiophysics and geophysics of ionogram spread F, Radio Sci., 31, 349-366, 1996.

Yamada, Y., 2-day, 3-day, and 5-6 day oscillations of the geomagnetic field detected by principal component analysis, Earth Planets Space, 54, 379 392, 2002.

G. G. Bowman and I. K. Mortimer (e-mail: ian@physics.uq.edu.au) 